\title{
EFFECTS OF BLENDED RICE BRAN OIL NEPTUNE LIGHT ON THE DYSLIPIDEMIA AMONG OVERWEIGHT AND OBESE ADULTS
}

\author{
Truong Hong Son*, Nguyen Xuan Ninh*, Luu Lien Huong* et al.
}

\section{ABSTRACT}

Objective: To assessment total cholesterol (TC), LDL-C, HDL, and triglyceride (TG) concentrations changed after using blended rice bran oil Neptune Light among dyslipidemia adults at different categories of obese. Methods: Forty-one adults with dual conditions (dyslipidemia and overweight/obese) from 40 to 60 years old received a $600-700 \mathrm{kcal}$ meal contained 20g/day Neptune Light rice bran oil for 60 days. Fasting blood samples and BMI was collected at baseline and every 30 days of trial. Results: Total cholesterol (TC), LDL-C and TG level declined by $0.5 \mathrm{mmol} / \mathrm{L} \quad(8.5 \%) ; 0.49$ $\mathrm{mmol} / \mathrm{L}(23.7 \%)$ and $0.55 \mathrm{mmol} / \mathrm{L}(32.0 \%)$, respectively after 60 days of intervention. The highest reduction of TC and TG was showed in the pre-obesity group, while the highest LDL-C reduction was shown in the obesity class II group. Conclusion: Using Neptune Light rice bran oil reduced TC, LDL-C and triglyceride level in overweight/obese adults from 40-60 years old after 60 days of intervention.

Keywords: Rice bran oil, hyperlipidemia, dyslipidemia, blood lipid profile, overweight/obese

\section{INTRODUCTION}

Hyperlipidemia is one of the leading risk factors for death and disability. Globally, high LDL cholesterol ranked $4^{\text {th }}$ out of 6 metabolic risks statistically by percent of death. In Vietnam, from 2010 to 2019, the

*Vietnam Institute of Applied Medicine

Responsible person: Truong Hong Son

Email: vienyhocungdung@gmail.com

Date of receipt: 20/7/2021

Date of scientific judgment: 11/8/2021

Reviewed date: $28 / 8 / 2021$ high LDL cholesterol (LDL-C) ranked $4^{\text {th }}$ and $5^{\text {th }}$ out of 6 metabolic risks statistically by percent of death, according to Global Burden of Diseases Statistics.

Hyperlipidemia was linked to being overweight or obese. According to the research of dyslipidemia status and related factors among adults over 30 years old in a Vietnamese urban region, cholesterol increases slowly in the underweight group and quickly in the overweight-obese group. Cholesterol level also increased in those with large arm circumference and a high waist-tohip ratio. The conclusion is that dyslipidemia may link to weight and that weight management is an essential factor in preventing dyslipidemia and cardiovascular disease.

Rice germ and rice bran are used to make rice bran oil. Rice bran accounts for roughly $10 \%$ of the rice and includes $18-22 \%$ oil. The color of rice bran oil (RBO) is light yellow. The oil is odorless at $200^{\circ} \mathrm{C}$, has an acid index of 0.50 , and a smoke point above $200^{\circ} \mathrm{C}$. RBO contains unsaturated fatty acids such as oleic acid (38.4\%), linoleic acid (34.4\%), and $\alpha$-linolenic acid (2.2\%), as well as saturated fatty acids such as palmitic acid (21. 5\%) and stearic acid (2.9\%). RBO contains small amounts of tocotrienols (72$612 \mathrm{ppm})$. Moreover, natural rice bran oil contains tocopherol (a substance known for its anti-hypertension) with the same amount as in soybean oil and other vegetable oils (100 mg\%) [1]. 
In both healthy and hyperlipidemic adults, consuming a diet rich in RBO causes a drop in plasma levels of TC and LDL. Choudhary comparing the effectiveness of a mixture of RBO and olive oil to regular cooking oil revealed that this mixture oil could lower total cholesterol by 3.7 percent, triglycerides by 9.5 percent, and LDL-C by 9 percent [2]. The results of 4 to 14-week studies on the effectiveness of RBO show that taking rice bran oil at a dose of up to $50 \mathrm{~g} /$ day reduces total cholesterol, LDL-C, triglycerides, and apolipoproteins while raising HDL-C [3].

$\mathrm{RBO}$ is becoming increasingly popular in Asia. To optimize lipid profiles, it is required to research and analyze the impacts and effectiveness of RBO produced in Vietnam. However, there is limited information in Vietnam about RBO and adult blood lipid profiles. As a result, we carried out a study in Hanoi to see how efficient it is to use mixed cooking oil products containing RBO on dyslipidemia in 40-60-year-old adults who are overweight or obese.

\section{MATERIALS AND METHODS}

\section{Study population:}

An online form was available for volunteers to register. Then, the volunteers were screened through anthropometry (height, weight, BMI). People with $\mathrm{BMI}>23$ (The WHO's BMI threshold for Asians) were subjected to further blood tests. Then, participants with total cholesterol concentration > $>5.2 \mathrm{mmol} / \mathrm{L}$, or LDL-C concentration $>2.58 \mathrm{mmol} / \mathrm{L}$ (as Defined by the Vietnam National Heart Association) were chosen. All of participants were explained about the aims of the study and signed in the informed consent. Forty-one adults from 40 to 60 years old with $\mathrm{BMI} \geq 23$ and higher in either total cholesterol or LDL$\mathrm{C}$ were collected. They were all on a regular diet and had no other conditions.

\section{Dietary intervention}

The subjects were given one meal and one snack six days per week, for 60 days. The meal has a total energy of $600-700$ kcals, with 400-500 kcals for lunch and 100-200 kcals for the snack. The daily meal contained 80 grams of white rice or brown rice, 100 grams of vegetables, 100 grams of protein sources such as meat/poultry/fish/shrimp, 20 grams of oil. Two eggs were also added to the meal every week. The nutritional value of the meal was determined using the Vietnam Food Composition Table 2016 and the Vietnamese People's Recommended Nutritional Intake in 2016. The meals were served at the VIAM nutrition clinic under supervision of research assistants. Subjects were encouraged not to change their diet, exercise habits, or daily activities during the trial.

Cooking oil used in our study was a mixture of rice bran oil with sunflower oil and soybean oil with at least $30 \%$ RBO named Neptune Light. This oil is manufactured by CALOFIC Company Ltd, and used for research purposes and has food safety certification. Subjects were not allowed to consume any other oils during trial. To ensure the use of provided oil, the subjects were given 1 liter of oil per household of 04 people every two weeks. Families with more than 04 people will be given 2 liters of oil every two weeks.

\section{Anthropometric measurement}

The Inbody $370 \mathrm{~S}$ machine was used to measure anthropometric indicators at 
baseline and then every 7 days. Bodyweight and height were measured to calculate body mass index (BMI). Body fat mass, percent body fat, and waist/hip ratio also were measured.

Laboratory analysis: Fasting blood test was collected at baseline and repeated on day of 30 and 60. Total cholesterol, LDL-C, HDL-C, and triglycerides concentration were determined. Classification of dyslipidemia according to the Vietnamese National Heart Association. All biochemical analyses were carried out at VIAM Clinical nutrition Lab, Hanoi, Vietnam.

Statistical Analysis: The data analysis included only individuals who ate at least
$80 \%$ of the meal ( $>48$ meals) and completed all the blood tests. Stata 12 software was used to analyze all statistical tests. Continuous variables are reported as Median and 95 percent $\mathrm{CI}$, while categories and percentages defined discontinuous variables. Wilcoxon sign rank test was used to determine the mean difference.

Ethical approval: The study was approved by the Ethics Council of Vietnam Institute of Applied Medicine.

\section{RESULTS}

All subjects completed the study, and none drop out after 60 days of intervention.

Table 1. Characteristics of subjects at baseline

\begin{tabular}{|c|c|c|}
\hline & $\mathbf{N}$ & $\%$ \\
\hline \multicolumn{3}{|l|}{ Gender } \\
\hline Male & 16 & 39,0 \\
\hline Female & 25 & 61,0 \\
\hline \multicolumn{3}{|l|}{ Age group } \\
\hline $40-50$ & 18 & 43,9 \\
\hline $50-55$ & 6 & 14,6 \\
\hline $55-60$ & 17 & 41,4 \\
\hline Mean of age & \multicolumn{2}{|c|}{$50,7 \pm 9,9$} \\
\hline \multicolumn{3}{|l|}{ BMI categorize } \\
\hline $\begin{array}{l}\text { Overweight } \\
(23 \leq \mathrm{BMI} \leq 24,9)\end{array}$ & 23 & 56,1 \\
\hline $\begin{array}{l}\text { Obesity class I } \\
(25 \leq \text { BMI } \leq 29,9)\end{array}$ & 15 & 36,6 \\
\hline $\begin{array}{l}\text { Obesity class II } \\
(\mathrm{BMI} \geq 30)\end{array}$ & 3 & 7,3 \\
\hline \multicolumn{3}{|l|}{ Lipid profiles } \\
\hline Higher TC & 22 & 55,0 \\
\hline Higher LDL-C & 26 & 65,0 \\
\hline Higher TG & 23 & 57,5 \\
\hline Lower HDL-C & 16 & 39,0 \\
\hline
\end{tabular}


Table 2: Changes of lipid profiles

\begin{tabular}{|l|c|c|c|c|}
\hline & D0 & D30 & D60 & D60-D0 \\
\hline TC $(\mathrm{mmol} / \mathrm{L})$ & 5,30 & $4,67 *$ & $4,67 *$ & $-0,5$ \\
& $(3,58 ; 6,88)$ & $(4,02 ; 5,96)$ & $(3,34 ; 6,44)$ & $(-1,95 ; 0,86)$ \\
\hline LDL-C & 3,56 & $3,0 *$ & $3,03^{*}$ & $-0,87$ \\
$(\mathrm{mmol} / \mathrm{L})$ & $(1,53 ; 6,26)$ & $(2,09 ; 3,90)$ & $(2,09 ; 4,26)$ & $(-2,72 ; 0,83)$ \\
\hline HDL-C (mmol/L) & 1,09 & 1,07 & $1,08(0,8 ; 1,58)$ & $-0,04$ \\
& $(0,71 ; 1,98)$ & $(0,79 ; 1,67)$ & $(-0,35 ; 0,29)$ \\
\hline Triglyceride & 1,87 & $1,65 *$ & $1,37 *$ & $-0,49$ \\
(mmol/L) & $(0,7 ; 6,29)$ & $(0,64 ; 3,45)$ & $(0,62 ; 3,84)$ & $(-3,38 ; 0,44)$ \\
\hline
\end{tabular}

Median, 95\% CI

*: $\mathrm{p}<0,05$; Wilcoxon test,

Table 2 showed that all TC, LDL, Triglyceride concentrations were significantly reduced $(p<0.05)$ after 30 days. From 30 days to 60 days of the intervention, the reduction remained stable at a statistically significant lower level $(\mathrm{p}<0.05)$ compared to the baseline. There was no significant change in HDL from the beginning to the end of the 60-day.

Table 3. Changes in blood lipid profiles according to BMI categories

\begin{tabular}{|c|c|c|c|c|}
\hline & DO & D30 & D60 & D60-D0 \\
\hline \multicolumn{5}{|c|}{ TC (mmol/L) } \\
\hline $\begin{array}{l}\text { Overweight } \\
(23 \leq \mathrm{BMI} \leq 24,9)\end{array}$ & $\begin{array}{c}5,43 \\
(4,05 ; 6,88)\end{array}$ & $\begin{array}{c}5,15^{*} \\
(4,11 ; 6,8)\end{array}$ & $\begin{array}{c}4,86^{*} \\
(3,35 ; 6,80)\end{array}$ & $\begin{array}{c}-0,46 \\
(-2,13 ; 0,82)\end{array}$ \\
\hline $\begin{array}{l}\text { Obesity } \\
(B M I \geq 25)\end{array}$ & $\begin{array}{c}5,2 \\
(3,58 ; 7,51)\end{array}$ & $\begin{array}{c}4,68 * \\
(3,34 ; 7,2)\end{array}$ & $\begin{array}{c}4,67 \\
(2,99 ; 6,24)\end{array}$ & $\begin{array}{c}-0,37 \\
(-2,32 ; 0,91)\end{array}$ \\
\hline \multicolumn{5}{|c|}{ LDL-C (mmol/L) } \\
\hline $\begin{array}{l}\text { Overweight } \\
(23 \leq \mathrm{BMI} \leq 24,9)\end{array}$ & $\begin{array}{c}3,61 \\
(2,04 ; 5,86)\end{array}$ & $\begin{array}{c}3,21 * \\
(2,35 ; 4,13)\end{array}$ & $\begin{array}{c}3,01 * \\
(2,09 ; 4,06)\end{array}$ & $\begin{array}{c}-0,87 \\
(-2,77 ; 0,8)\end{array}$ \\
\hline $\begin{array}{l}\text { Obesity } \\
(B M I \geq 25)\end{array}$ & $\begin{array}{c}3,75 \\
(1,52 ; 6,81)\end{array}$ & $\begin{array}{c}2,88 \\
(1,99 ; 4,4) \\
\end{array}$ & $\begin{array}{c}2,97 \\
(1,59 ; 4,47)\end{array}$ & $\begin{array}{c}-1,22 \\
(-2,97 ; 1,11)\end{array}$ \\
\hline \multicolumn{5}{|c|}{ HDL-C (mmol/L) } \\
\hline $\begin{array}{l}\text { Overweight } \\
(23 \leq \mathrm{BMI} \leq 24,9)\end{array}$ & $\begin{array}{c}1,16 \\
(0,71 ; 2,12)\end{array}$ & $\begin{array}{c}1,12 \\
(0,79 ; 1,70)\end{array}$ & $\begin{array}{c}1,16 \\
(0,9 ; 1,78)\end{array}$ & $\begin{array}{c}-0,03 \\
(-0,49 ; 0,49)\end{array}$ \\
\hline $\begin{array}{l}\text { Obesity } \\
(B M I \geq 25)\end{array}$ & $\begin{array}{c}1,06 \\
(0,5 ; 1,54)\end{array}$ & $\begin{array}{c}1,03 \\
(0,77 ; 1,39)\end{array}$ & $\begin{array}{c}1,03 \\
(0,76 ; 1,56)\end{array}$ & $\begin{array}{c}-0,01 \\
(-0,35 ; 0,47)\end{array}$ \\
\hline \multicolumn{5}{|c|}{ Triglyceride (mmol/L) } \\
\hline $\begin{array}{l}\text { Overweight } \\
(23 \leq \mathrm{BMI} \leq 24,9)\end{array}$ & $\begin{array}{c}1,66 \\
(0,66 ; 8,58)\end{array}$ & $\begin{array}{c}1,47^{*} \\
(0,66 ; 4,04)\end{array}$ & $\begin{array}{c}1,30 * \\
(0,75 ; 3,84)\end{array}$ & $\begin{array}{c}-0,55 \\
(-4,63 ; 0,44)\end{array}$ \\
\hline $\begin{array}{l}\text { Obesity } \\
(B M I \geq 25)\end{array}$ & $\begin{array}{c}2,04 \\
(0,76 ; 5,16)\end{array}$ & $\begin{array}{c}1,69 * \\
(0,53 ; 4,0)\end{array}$ & $\begin{array}{c}1,64 \\
(0,69 ; 3,96)\end{array}$ & $\begin{array}{c}-0,43 \\
(-3,48 ; 1,86)\end{array}$ \\
\hline
\end{tabular}

Median, 95\% CI

$*$ : $\mathrm{p}<0,05$, Wilcoxon test

Table 3 showed that the level of TC, LDL-C, and triglycerides reduced significantly in the overweight group but not in the obese or overweight groups. 
No1\&2/2021 VIETNAM MEDIGAL JOURNAL

Table 4: The different of anthropometric and body composition

\begin{tabular}{|l|c|c|c|c|}
\hline & D0 & D30 & D60 & D60-D30 \\
\hline Weight (kg) & $63,5(52,5 ; 89,0)$ & $61,8(51,5 ; 87,7)^{\mathrm{a}}$ & $61,8(50,2 ; 85,2)^{\mathrm{a}}$ & $-1,6(-3,6 ; 0,3)$ \\
\hline BMI (kg/m²) & $24,1(23 ; 30,2)$ & $24,3(22,7 ; 29,8)^{\mathrm{a}}$ & $23,6(22,5 ; 29,3)^{\mathrm{a}}$ & $-0,6(-1,4 ; 0,1)$ \\
\hline $\begin{array}{l}\text { Body fat mass } \\
\text { (kg) }\end{array}$ & $19,3(13,7 ; 32,0)$ & $18,9(14,0 ; 29,5)^{\mathrm{a}}$ & $18,7(13,4 ; 28,0)^{\mathrm{a}}$ & $-0,8(-2,9 ; 0,8)$ \\
\hline $\begin{array}{l}\text { Percent Body } \\
\text { fat (\%) }\end{array}$ & $31,3(20,9 ; 41,2)$ & $31,3(21,6 ; 41,6)^{\mathrm{a}}$ & $31,8(21,41,7)^{\mathrm{a}}$ & $-0,4(-2,9 ; 1,8)$ \\
\hline Waist/hip ratio & $0,88(0,82 ; 0,94)$ & $0,87(0,81 ; 0,92)$ & $0,89(0,82 ; 0,94)$ & $0(-0,02 ; 0,04)$ \\
\hline
\end{tabular}

Median and 95\%CI

a: $\mathrm{p}<0,05$

Compared to the beginning of the study, weight, BMI, body fat mass, and percent body fat all had statistically significant changes, however after 30 days and 60 days there was no difference. There was no improvement in waist/hip circumference after both 30 days and 60 days of intervention.

\section{DISCUSSION}

In our study, the changes were observed in TC, TG, and LDL-C, however no change in HDL was found. The second results including anthropometry and body composition had interesting points. After the first 30 days of intervention by Neptune Light oil, the level of BMI, body fat mass and percent body fat decreased statistically significantly compared to baseline $(\mathrm{p}<0.05)$. However, during the next 30 days, this effect was unchanged.

Fat is a vital component for patients with dyslipidemia, although it is frequently limited in their diet. The amount of fat used in our study was $20 \mathrm{~g}$ regardless of the amount of fat in the food, but it still positively affected lipid profiles. Thus, it can be said that people with dyslipidemia can still consume the same amount of fat as healthy people. Consuming the right type of fat is more important than the right amount of fat. Our cooking oil was a combination of rice, soybean, and sunflower oils, all of which have been found to improve heart health and blood lipids.

Diet has a noticeable impact on blood lipid levels as well as the risk of cardiovascular disease. Reduce saturated fat by roughly $7 \%$ of total caloric intake and restrict cholesterol consumption to lower than $200 \mathrm{mg} /$ day with Western-style meals were found to lower LDL-C levels by $9-12 \%$ [4]. Total cholesterol levels were primarily influenced by saturated and polyunsaturated fat consumption and dietary cholesterol food for daily consumption. A meta-analysis of 60 clinical trials indicated that substituting polyunsaturated fats from non-hydrogenated cooking oils for trans fats was the most effective strategy to improve blood lipid levels [5].

Using Neptune Light oil which had blend RBO, according to our research, is an effective strategy to minimize trans-fat and saturated fatty acid consumption in the diet. Blended RBO are high in monounsaturated fats (MUFAs) and polyunsaturated fats (PUFAs) and low in saturated fat (SFAs). SFAs intake might increase total serum cholesterol, whereas PUFAs intake might lower cholesterol levels compared to the same number of calories from carbs. 
According to Suzuki and Oshima [6], RBO had an effect on the prevention of hyperlipidemia in young Japanese women. After seven days of using a $60 \mathrm{~g}$ mixture of RBO and safflower oil (70:30 ratio) TC had reduced substantially. A systematic review pooled results from other studies indicate that consuming $50 \mathrm{~g}$ of rice bran oil per day for 414 weeks decreased TC, LDL-C, TG and apolipoprotein levels while increasing HDL$\mathrm{C}$ levels [3]. Choudhary evaluated the effectiveness of a blend of brown rice and olive oil to ordinary cooking oil and found that it could lower total cholesterol by $3.7 \%$, triglycerides by $9.5 \%$, and LDL-C by $9 \%$ [2]. A randomized controlled trial evaluating the lipid-improving and antioxidant potential of rice bran oil in hyperlipidemic patients also showed an effect of unsaturated fats in lowering LDL-C levels, increasing antioxidant levels in the body, and reducing risk factors for cardiovascular diseases [7]. Despite changes in research design, duration, and the amount of oil used in the interventions, RBO and blended RBO consistently exhibited decreased lipid profiles.

Gamma Oryzanol is considered the most crucial active compound of rice bran oil. According to Chen and Cheng, gamma oryzanol can influence cholesterol and bile acid excretion in the feces. Gamma oryzanol can considerably boost bile acid and neutral sterol excretion. Enhanced expression of LDL receptors in the liver, which leads to LDL-lowering and increased CYP7A1 expression, could explain rice bran oil's lipidlowering capability. The first step in the endogenous cholesterol pathway in the liver, which converts cholesterol to bile acids, is catalyzed by the CYP7A1 protein. This process regulates homeostasis cholesterol catabolism and synthesis. Ishihara [8] investigated the effect of $300 \mathrm{mg}$ gammaoryzanol supplementation on 40 women with postmenopausal syndrome for 4-8 weeks. The results showed that in hyperlipidemic subjects, plasma concentration of TC, LDL-C and $\mathrm{TG}$, and lipid peroxide decreased significantly while HDL-C increased

Another active component discovered in RBO is phytosterol. Due to the structural similarity to cholesterol, phytosterols can replace cholesterol in intestinal micelles and modify cholesterol production. By inhibiting the activity of the cholesterol esterase enzyme, phytosterols can also prevent cholesterol from being esterified intracellula.

Increased intake of antioxidants in the diet, such as vitamin E, has recently been recommended to prevent atherosclerosis. Oxidative damage is also a crucial factor in cardiovascular illnesses such arterial stiffening. Vitamin E isomers in RBO (such as tocopherol and toccotrienol) may also have antioxidant properties similar to vitamin E. Tocotrienol may lower total cholesterol by blocking an enzyme that regulates cholesterol synthesis in the body.

Because of the cost savings, blending rice bran oil with other oils to save money is becoming increasingly popular. When blended with other vegetable oils such as olive oil, peanut oil, sunflower oil, and sesame oil, rice bran oil has been shown to increase the quality of the oil combination in terms of fatty acid content and antioxidant capacity [3].

Most of the research suggested that increasing the amount of naturally occurring vegetable fats in the diet (including vegetable fats from RBO) has no effect on body weight or body fat in elderly or overweigh/obese people. The effects of RBO on weight are 
only studied in animals. To assess the effect of RBO on anthropometric indexes, further studies over a longer period are required.

\section{CONCLUSION}

In overweight/obese individuals aged 4060 years, using Neptune Light blended rice bran oil can help to lower total cholesterol, LDL, and triglycerides. However, to confirm the exact effects of RBO, studies with larger sample sizes, more strictly controlled and focusing on pure rice bran oil are required.

\section{CONFLICT OF INTEREST}

There is no conflict of interest.

\section{ACKNOWLEDGEMENT}

We would like to thank professors Tuong Duy Pham, Lam Nguyen Thi, Do Ba Ho, Trung Tran Quang and Hoan Van Pham who have valuable comments to complete this study. We also thank to colleagues and board of chief from VIAM Clinic for their contribution to this study. Special thanks to FIT City nutrition company for their support in meal preparation.

\section{REFERENCES}

1. Cicero, A.F. and A. Gaddi, Rice bran oil and gamma-oryzanol in the treatment of hyperlipoproteinaemias and other conditions. Phytother Res, 2001. 15(4): p. 277-89.

2. Monika Choudhary, Kiran Grover, and Jasvinder Sangha, Effect of Blended Rice Bran and Olive Oil on Cardiovascular Risk Factors in Hyperlipidemic Patients. Scientific Research, 2013. 4(11).

3. Amanat Ali and Sankar Devarajan, Nutritional and Health Benefits of Rice Bran Oil. Vol. Brow Rice. 2017: Spinger. 135-158.

4. Van Horn, L., et al., The evidence for dietary prevention and treatment of cardiovascular disease. J Am Diet Assoc, 2008. 108(2): p. 287-331.

5. Mensink, R.P., et al., Effects of dietary fatty acids and carbohydrates on the ratio of serum total to HDL cholesterol and on serum lipids and apolipoproteins: a meta-analysis of 60 controlled trials. Am J Clin Nutr, 2003. 77(5): p. 1146-55.

6. Suzuki $\mathbf{S}$ and Oshima $\mathbf{S}$ Influence of blending of edible fats and oils on human serum choles-terol level (part 2). Jpn J Nutr, 1970. 28.

7. Bumrungpert, A., et al., Rice Bran Oil Containing Gamma-Oryzanol Improves Lipid Profiles and Antioxidant Status in Hyperlipidemic Subjects: A Randomized Double-Blind Controlled Trial. J Altern Complement Med, 2019. 25(3): p. 353-358.

8. Ishihara M, et al., Clinical effect of gammaoryzanol on climacteric disturbance on serum lipid peroxides. Nihon Sanka Fujinka Gakkai Zasshi 1982. 34(2). 